\title{
Knowledge of Pharmacy Staff Regarding Over the Counter Medications in Erbil City
}

Araz Abdulmajid Aziz; Department of Community Nursing, College of Nursing, Hawler Medical University, Erbil, Iraq. (Correspondence: araz.abdulmajed@gmail.com)

Salih Ahmed Abdulla; Department of Community Nursing, College of Nursing, Hawler Medical University, Erbil, Iraq.

\begin{abstract}
Background and objectives: Use of over the counter (OTC) medications is an important area for research within different health care systems. It is also associated with increased risk of abuse and medication addiction. The need to avoid unnecessary exposure to medication is a concern among the health-care community, in which pharmacy staff plays first line of response and their knowledge is critical. In Kurdistan region of Iraq, other medical and to some extend non-medical staff also works in pharmacies which may affect their scientific understanding of medication. The current study aims to determine the knowledge of pharmacies staff regarding OTC medication use in Erbil city.

Methods: Across-sectional study was conducted from 15th- October 2018 to 15th October 2019. A sample of 187 pharmacies in Erbil city Centre was recruited through a systematic random sampling technique. Data were collected through direct interview with participants, A questionnaire was used for interviewing the pharmacy staff about sociodemographic characteristics and knowledge regarding OTC medications. The validity and reliability of the instrument was checked. Data were analyzed by using the software system of Statistical Package for Social Science (SPSS version 23).

Results: The total number of the studied sample was 187 medical and para-medical staff working in Erbil pharmacies. Their mean age + SD were $28.56+5.33$ years, ranging from 18 to 45 years. Generally only quarter $(25 \%)$ of the whole sample had good level of knowledge. less than one third (29.4\%) of the sample knew the correct definition of the OTC. Only $28.3 \%$ of the sample thinks that the OTC medications mostly cause side effects. Good level of knowledge was significantly associated with being female, and being a graduate and with being a specialized pharmacist.

Conclusion: There is a limited knowledge about OTC medications among staff working in pharmacies. However among other specialties (nurses and paramedic) specialist pharmacist had higher level of knowledge regarding OTC.
\end{abstract}

Key words: Self-medication, OTC, Knowledge, Pharmacy

Received: 19/8/2019

Accepted: 13/10/2019

Published: 30/11/2019

\section{INTRODUCTION}

Over the Counter (OTC) medications are defined as the medications available, and obtained without a physician prescription. Over the counter medications can be used with appropriate caution and proper dosages. However many do not know the dangers of misuse and continue to use OTC medications [1]. Before the Food and Drug
Administration (FDA) existed in the united states, all medications were allowed to be self-medicated; alcohol, cocaine, marijuana, and opium were included in some OTC products without notification to users. For example, in the United States of America, products containing over 80 active ingredients of different therapeutic groups were switched from prescription-only to OTC 
status between 1976 and 2000. In 2007, a new law in United States of America became effective that required companies to report serious adverse events associated with OTC medications, from there the law and regulation of OTC medications was issued [2].In a study conducted by Knapp, (1998), found that, in the early 1970s analgesics, cold remedies, and laxatives were frequently and commonly found in American homes, [7]. Referring to the study conducted in Malaysia in 2015, almost $60 \%$ respondents believed that OTC medications are safe [6].People mostly reach for self-care products to help themselves their common health problems which include fever, body pains, diarrhea, vomiting, cough, indigestion and upper respiratory tract infections. This is because it is considered easier, more cost-effective, timesaving, or the problem may seem too unimportant to require making an appointment with a healthcare profession, and in other cases, they may have few or no other options[8].Several studies on the subject indicate that there are risks such as misdiagnosis, drug resistance, and use of medications in excessive amounts, use of expired medications, prolonged duration of use, and medication interactions[3].OTC medications are consumed by adults almost in everyday life, referring to a study conducted in Maldives, in 2016; 76.6\% of the 192respondents took OTC medications. In another study conducted in Jordan in 2011, the results revealed that $49.0 \%$ used left-over self-medication without physician's consultation, while $51.8 \%$ use selfmedication based on a relative's advice [4].According to the FDA, as with prescribed medication there are many health risks related to the use of OTC medications such as: gastrointestinal problems, effect on kidney function, liver problem and risk of cardio vascular events[5].While people know the risks of OTC medications they use
OTC medications for various reasons including because it is cheaper than the prescribed medication. Knowing the knowledge of people regarding OTC medications will help in exploring ways of awareness rising and conducting actions to reduce this phenomenon in our community. The study aims to determine the knowledge of pharmacy staffregarding over the counter medication use in Erbil city. While the specific objectives were to find out the most common medications and indications used as OTC drugs among users and to find out the association between socio-demographic characteristics of pharmacy staff and knowledge regarding OTC medications.

\section{METHODS}

A quantitative descriptive cross-sectional study was used to assess the knowledge of the pharmacy staff on over the counter medications in from October 2018 to October 2019 in different locations in Erbil city. The study sample consisted of 187 pharmacy staff (pharmacist, nurse, paramedical staff) in Erbil city center, who were selected using systematic random sampling, according to the study's inclusion and exclusion criteria. The study targeted pharmacy staff selling medication in pharmacies in Erbil city center and staff working during evening shifts upon providing their informed consent. The sample size was estimated based on the formula of. In which is standard normal variety at $5 \%$ type one error when proportion with a $95 \%$ level of confidence and a margin of error of $5 \%,=1.96$. $\mathrm{P}$ value $<0.05$. The $d$ is the absolute error and it's equal to 0.05 . And the $p$ stands for the expected portion of population based Pharmacy syndicate, there is 373 pharmacies in Erbil city center, which is $86.4 \%$ of all pharmacies in Erbil (432), thus the $p=0.86 \%$. And based 
on this formula the study sample will be 187 pharmacies in Erbil city center, which had been selected using systematic random sampling, 373/187=2 each second pharmacy will be recruited. A pilot study was conducted on 10 pharmacies. Internal consistency of the study was obtained through applying Pearson correlation ( $r$ ) which was (0.74); it indicates that there was a medium positive correlation. Direct face to face interview through questionnaire was conducted by researcher and separately with each of participated candidate for at least 25 to 30minutes; the interview took place in a private pharmacy. The questionnaire consisted of two parts. The first part was on socio-demographic characteristics of Study Sample. This part composed of questions about the age of the participants, the occupation, and level of education, residential area, income, and years of working experience. The second part assessed the knowledge of the pharmacy staff regarding OTC medications, which was consisted of 8items which are concerned with issue of the knowledge of the Pharmacy staff regarding OTC. The questions included; knowledge about the side effects, consumption, use, prescription, indications, and other information regarding OTCs. Multiple and best answer choice were designed to obtain the participants response to the specific questions. Each correct answer was equal to one score and total result were from 23 scores with the segregation of poor knowledge ( $\leq 7$ scores), fair knowledge,(8-15 scores), and good knowledge (16-23 scores). The questionnaire was validated through a panel of ten experts in different fields to investigate the content of questionnaire for its clarity, relevancy, and adequacy. The expert's responses were evaluated based on their agreements or disagreements. Results had indicated that the majority of the experts agreed upon the items of the study instrument. The changing of the instrument was mostly in the Knowledge part where the experts added and modified some questions which were general to be more knowledge directed. Prior of data collection, ethical approval was obtained from ethical and scientific committee of College of Nursing / Hawler Medical University. Furthermore, the informed oral consent was taken from the candidates who participated in the study, after confirmation of confidentiality, anonymity and participants self-determination by the researcher. Also formal approval was obtained from Kurdistan pharmacists syndicate (No:561, 20/12/2018) and Erbil pharmacists syndicate (No: 1828, 26/12/2018).

The statistical package for social science (SPSS, Version 23) was used for data processing and statistical analysis. The statistical analysis included descriptive statistical analysis such as frequency and percentage to describe the basic features of the data in a study and provide simple summaries about the sample and the measures, Inferential statistical analyses as Chi-square and fisher exact test were implemented to make judgment about inferences from our data to more general conditions. The confidence interval was $95 \%$. The P-value of each test $\leq 0.05$ considered statistically significant.

\section{RESULTS}

The sample consist of 187 medical and para-medical staff working in Erbil pharmacies (one staff was selected per each pharmacy according to the availability of the staff). Their mean age + SD was 28.56 +5.33 years, ranging from 18 to 45 years. The highest proportion of the sample (33.7\%) was aged 25 to 29 years, and only $11.2 \%$ were aged greater than or equal to $\geq 35$ years. The majority $(73.3 \%)$ of the sample were males. Around two thirds 
(62\%) of the sample were college graduates, and only two personnel (1.1\%) were graduates of primary school. Table (1) shows that $27.8 \%$ of the sample was pharmacists, and the rest were paramedical staff of different qualifications, except for $10.2 \%$ of the sample who were not related to the medical field. It is evident in the mentioned table that $62 \%$ of the sample were originally from urban settings, and $24.1 \%$ of the sample mentioned that their income was not sufficient for daily needs.

Regarding the OTC medications and their side effects, Table 2 shows that; less than one third (29.4\%) of the sample knew the correct definition of the OTC medications which is 'any medication that people can purchase without prescription' as presented in, as for the probable side effects, only $28.3 \%$ of the sample think that the OTC medications may cause side effects while (71.1\%) thought that these medications sometimes cause side effects. The following side effects of the OTC medications had been mentioned by the pharmacy staff: allergy (82.4\%), tremor $(12.8 \%)$, swelling of the face and limbs (15\%), abdominal pain (58.3\%), insomnia (15\%), sweating (15\%), liver damage (24.1\%), nausea and vomiting (64.2\%), and difficult breathing (18.7\%).

Table 1:Basic characteristics of the studied sample

\begin{tabular}{|c|c|c|}
\hline & No. & $(\%)$ \\
\hline \multicolumn{3}{|l|}{ Age } \\
\hline$<25$ & 49 & $(26.2)$ \\
\hline $25-29$ & 63 & $(33.7)$ \\
\hline $30-34$ & 54 & $(28.9)$ \\
\hline$\geq 35$ & 21 & $(11.2)$ \\
\hline \multicolumn{3}{|l|}{ Gender } \\
\hline Male & 137 & (73.3) \\
\hline Female & 50 & $(26.7)$ \\
\hline \multicolumn{3}{|l|}{ Educational level } \\
\hline Primary school & 2 & (1.1) \\
\hline Intermediate school & 6 & (3.2) \\
\hline Secondary school & 3 & $(1.6)$ \\
\hline Institute & 60 & (32.1) \\
\hline College & 116 & $(62)$ \\
\hline \multicolumn{3}{|l|}{ Occupation (title) } \\
\hline Pharmacist & 52 & $(27.8)$ \\
\hline Assistant Pharmacist (institute) & 36 & $(19.3)$ \\
\hline Nurse (college) & 53 & $(28.3)$ \\
\hline Paramedical staff (institute) & 27 & $(14.4)$ \\
\hline Others (not related to medical field) & 19 & $(10.2)$ \\
\hline \multicolumn{3}{|l|}{ Residency } \\
\hline Urban & 116 & (62) \\
\hline Rural & 71 & (38) \\
\hline \multicolumn{3}{|l|}{ Income } \\
\hline Not sufficient & 45 & (24.1) \\
\hline Sufficient & 111 & $(59.4)$ \\
\hline Exceeds needs & 31 & $(16.6)$ \\
\hline
\end{tabular}


Table 2: Definition of OTC medications and their side effects

No.

(\%)

OTC medications definition

Any medication prescribed by medical professional

Any medication that people can buy without prescription

Probable side effects

Sometimes cause side effect

Mostly cause side effect

Never cause side effect

Allergy

Yes

No

Tremor

Yes

No

Abdominal pain

Yes

No

Insomnia

Yes

No

Yes

Liver damage

Yes

No

Nausea and vomiting

Yes

No

Difficult breathing

Yes

No
35

97

55

53

152 
Meanwhile; when the study sample were asked about OTC indicator, their answers as it demonstrated in Table 3 show that, the highest proportion (46.5\%) of the staff thought that minor illnesses were the main indication for the OTC medications, and $27.3 \%$ of the staff thought that infections were the main indication for the OTC medications.
Meanwhile as showed in Table 4, the majority $(73.8 \%)$ of the staff believed that headache was the most common first indication for the OTC medications, and $36.9 \%$ had chosen cold, cough, and sore throat as the second indication, while $23.1 \%$ and $22 \%$ of the staff had chosen body pain and fever, respectively, as the third indication of the OTC medications.

Table 3: General OTC medications indications

\begin{tabular}{lcc}
\hline & No. & (\%) \\
\hline OTC indications & & \\
Hereditary disease & 11 & $(5.9)$ \\
Minor Illness & 87 & $(46.5)$ \\
Heart diseases & 3 & $(1.6)$ \\
Gl diseases & 35 & $(18.7)$ \\
Infections & 51 & $(27.3)$ \\
\hline
\end{tabular}

Table 4: Top three most common OTC medications indications

\begin{tabular}{|c|c|c|}
\hline & No. & (\%) \\
\hline \multicolumn{3}{|l|}{ First most common indication } \\
\hline Headache & 138 & $(73.8)$ \\
\hline Fever & 15 & (8) \\
\hline Cold, cough & 25 & $(13.4)$ \\
\hline Body pain & 1 & $(0.5)$ \\
\hline Joint pain & 3 & (1.6) \\
\hline HTN & 1 & $(0.5)$ \\
\hline GI problem & 4 & (2.1) \\
\hline \multicolumn{3}{|c|}{ Second most common indication } \\
\hline Headache & 23 & $(12.3)$ \\
\hline Fever & 24 & $(12.8)$ \\
\hline Cold, cough, and sore throat & 69 & $(36.9)$ \\
\hline Body pain & 34 & $(18.2)$ \\
\hline Menses' symptoms & 6 & (3.2) \\
\hline Joint pain & 9 & (4.8) \\
\hline GI problems & 22 & $(11.8)$ \\
\hline \multicolumn{3}{|l|}{ Third most common indication } \\
\hline Headache & 6 & (3.3) \\
\hline Fever & 40 & $(22)$ \\
\hline Cold, cough, sore throat & 25 & $(13.7)$ \\
\hline Body pain & 42 & $(23.1)$ \\
\hline Menses' symptoms & 9 & (4.9) \\
\hline Joint pain & 28 & (15.4) \\
\hline DM & 2 & (1.1) \\
\hline HTN & 4 & $(2.2)$ \\
\hline Gl problems & 26 & $(14.3)$ \\
\hline
\end{tabular}


Regarding the knowledge of study sample about the proper person to decide on OTC medication consuming, Table 5 revealed that, $36.4 \%$ of the pharmacy staff think that the consumer is the person who decide to use the OTC medications (which is the correct response), while $42.8 \%$ thought that the pharmacist is the person who chose the medications. Knowledge about OTC medications that are considered as OTC was as follows: antacids (69\%), cough syrups $(58.3 \%)$, vitamins and food supplements (46\%), decongestants (42.2\%), and herbal products (26.2\%).
The other groups of drugs are not considered as OTC medications but in spite of that $70.6 \%$ and $66.3 \%$ of the staff considered the analgesics and antibiotics, respectively, as OTC medications (Table 5). Considerable proportions of the pharmacy personnel considered the anti-diabetics and the antihypertensive medications as OTC medications ( $14.4 \%$ and $12.3 \%$ respectively). Figure 1 shows that $43.6 \%$ of the study sample had poor knowledge about the OTC medications, and only $25 \%$ of the whole sample had good level of knowledge.

Table 5:The OTC list

\begin{tabular}{llc}
\hline Group of medications considered as OTC by the pharmacy staff $(\mathbf{n}=\mathbf{1 8 7})$ & No & (\%) \\
\hline Analgesics & 132 & $(70.6)$ \\
Antacids* & 129 & $(69)$ \\
Antibiotics & 124 & $(66.3)$ \\
Cough syrups* & 109 & $(58.3)$ \\
Vitamins and food supplements* & 86 & $(46)$ \\
Decongestants* & 79 & $(40.1)$ \\
Laxatives & 75 & $(39.6)$ \\
Antidiarrheal & 74 & $(29.9)$ \\
Antihistamines & 56 & $(28.3)$ \\
Antiemetic medications & 53 & $(26.2)$ \\
Herbal products* & 53 \\
Anti-diabetics & 49 & $(14.4)$ \\
Oral contraceptives & 27 & $(13.4)$ \\
Antihypertensive medications & 25 & $(12.3)$ \\
\hline
\end{tabular}

*Included in the list of the OTC medications

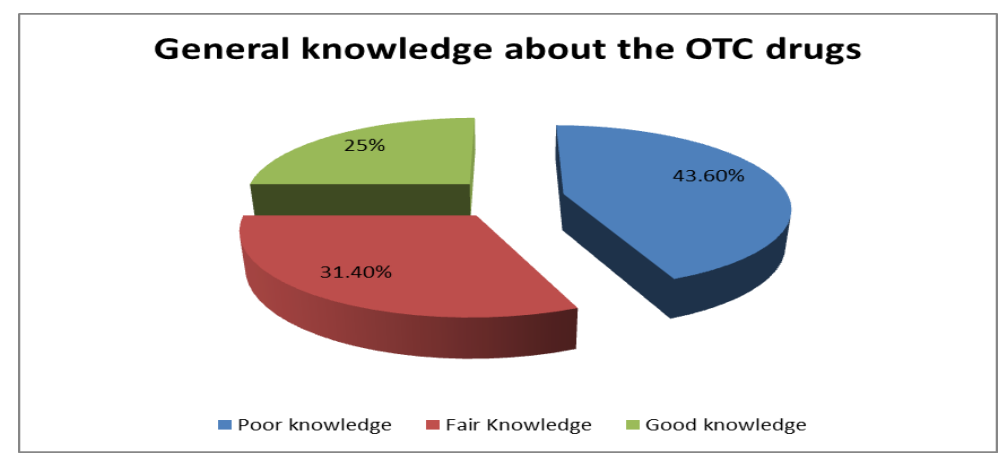

Figure 1: General knowledge of the study sample about the OTC 
It is worth to mention that $29.6 \%$ of those aged 30-34 years had good level of knowledge (Table 6) which is more than the other age categories. The same table shows that $32 \%$ of females had a good level of knowledge compared with $13.1 \%$ of males $(p=0.003)$. It is clear that none of those with low levels of education had good level of knowledge, while $25 \%$ of the college graduates had good level of knowledge $(p=0.046)$.
The same can be applied for occupation, where $46.2 \%$ of the pharmacists who are college graduates had good level of knowledge $(p<0.001)$. A non-significant association was detected between age and the knowledge level ( $p=0.063$ ), also a non-significant association was detected between the level of knowledge with participation in medical courses ( $p=0.096)$, residency $(p=0.110)$, and income $(p=$ $0.347)$.

Table6: The relationship between the demographic characteristic and the overall level of knowledge

\begin{tabular}{|c|c|c|c|c|c|}
\hline \multirow[b]{2}{*}{ Age } & \multicolumn{2}{|c|}{$\begin{array}{l}\text { Poor and Fair } \\
\text { knowledge }\end{array}$} & \multicolumn{2}{|c|}{ Good knowledge } & \multirow[b]{2}{*}{ P-volue } \\
\hline & No. & (\%) & No. & $(\%)$ & \\
\hline$<25$ & 44 & (89.8) & 5 & $(10.2)$ & \\
\hline $25-29$ & 53 & (84.1) & 10 & (15.9) & \\
\hline $30-34$ & 38 & (70.4) & 16 & $(29.6)$ & \\
\hline$\geq 35$ & 18 & (85.7) & 3 & (14.3) & 0.063 \\
\hline \multicolumn{6}{|l|}{ Gender } \\
\hline Male & 119 & (86.9) & 18 & $(13.1)$ & \\
\hline Female & 34 & (68) & 16 & (32) & 0.003 \\
\hline \multicolumn{6}{|l|}{ Education } \\
\hline Primary & 2 & $(100)$ & 0 & (0) & \\
\hline Intermediate & 6 & $(100)$ & 0 & (0) & \\
\hline Secondary & 3 & $(100)$ & 0 & (0) & \\
\hline Institute & 55 & (91.7) & 5 & $(8.3)$ & \\
\hline College and above & 87 & $(75)$ & 29 & $(25)$ & 0.046 \\
\hline \multicolumn{6}{|l|}{ Occupation } \\
\hline Pharmacist & 28 & $(53.8)$ & 24 & $(46.2)$ & \\
\hline Assistant pharmacist & 33 & (91.7) & 3 & (8.3) & \\
\hline Nurse & 51 & $(96.2)$ & 2 & (3.8) & \\
\hline Paramedic & 24 & (88.9) & 3 & (11.1) & \\
\hline Other & 17 & (89.5) & 2 & (10.5) & $<0.001$ \\
\hline \multicolumn{6}{|l|}{ Medical course } \\
\hline Yes & 41 & (74.5) & 14 & $(25.5)$ & \\
\hline No & 112 & $(84.8)$ & 20 & $(15.2)$ & 0.096 \\
\hline \multicolumn{6}{|l|}{ Residential area } \\
\hline Urban & 99 & $(85.3)$ & 17 & $(14.7)$ & \\
\hline Rural & 54 & (76.1) & 17 & $(23.9)$ & 0.11 \\
\hline
\end{tabular}

*fisher's exact test 


\section{DISCUSSION}

Self-medication is the practice where individuals treat their illnesses with medications which are approved and available without prescription, and which are safe and effective when used as per direction [9]. However they may result in unwanted effects if inappropriately used. Pharmacy staff comes across many consumers who request medication without prescription, some which are allowed and some which are forbidden; thus pharmacy staff knowledge plays the most important role in consumers' safety regarding medication consumption. The current study aimed at assessing the knowledge of pharmacy staff regarding the OTC. Result indicated that only one quarter of the sample had a good level of knowledge while the rest had poor to fair knowledge level, where in a study conducted in India by Ravichandran and Basavareddy, (2016)their result showed higher rate of knowledge regarding the OTC definition, where among the pharmacists holding bachelor degree, 69\% were able to define OTC correctly whereas only $31 \%$ of D. Pharmacy degree holders could define OTC [10]. However according to the researcher such differences is that the study conducted in India targeted only the pharmacist, while the current study also included other specialist as in Erbil not only pharmacist works in the pharmacies. No significant association was detected between age and the knowledge level, but it is worth to mention that those in third decay of their age had more advanced level of knowledge that the other age groups. this result was similar to a study conducted in Iran about the pharmacy staff knowledge of sport supplement (a type of OTC) where their result also showed that lower age associated with lesser knowledge level [11]. Meanwhile the result of current study was different from a study conducted in India where knowledge of pharmacist were assessed specifically regarding OTC side effects, in which Bj et al., (2012) found that knowledge association is more in the age group 21 to 30 years (mean \pm SD 5.16 \pm 2.89 ) and least was found in the age group of 51 to 60 years with mean score of (mean $\pm 3.33 \pm 4.16$ years) [12]. While age has a direct relationship with years of experience, age was not associated with good knowledge level or practice skill of the pharmacy staff in this study. It was assumed that age association is different per studies as each study have selected different age group, and also number of study sample plays role in the differences. This study also revealed that regarding the sex of participants, females were more knowledgeable of the OTC, than the males, and the results were statistically very significant. This result was similar to a study conducted by Ali et al (2012) in Malaysia. Which showed that males had lower level of knowledge than females [13]. However, the results contradict with findings observed by Boateng (2009), which indicated that females were more susceptible to self-medication due to strenuous job requirement[14].Females might be keener on continuous updating of the knowledge, and are more capable of memorizing and focusing on contentious education which resulted in having more knowledge than the males. As for the probable side effects, less than onethird of the sample knew that, the OTC medications mostly cause side effects. The majority of the sample study indicated allergies as one of the most common side effects of the OTC medications, while half of them included abdominal pain as major side effect, and around two-thirds of the study sample indicated that nausea and vomiting are also one of the most common side effects of the OTC. This study's results were similar to those found in a cross sectional study conducted 
in India medications which revealed that the staff working in pharmacies are very aware $(68.5 \%)$ about the adverse effect or side effect of medication [15]. No participants with low levels of education had good level of knowledge, while only quarter of the college graduates had good level of knowledge. The same can be applied for occupation, where less than half of the pharmacists who are college graduates had good level of knowledge. According to the researcher it's linked to the advanced and different education type which were received by different pharmacy workers. And also this difference among the pharmacy staff maybe it's due to the fact that there were workers with no medical or health background. No significant association was detected between the level of knowledge with participation in medical courses, residency, and income. However no similar studies were available to compare the current results with previous work; in the time that the researcher highlights this as a study limitation, yet it's necessary to mention that during literature review almost all previous studies conducted by other researchers were about knowledge of community, or medical students about OTC, rather than the pharmacy staff, assuming that in most of the countries there is strong system for the pharmacy expending of OTC, thus the focus of researches is less on the performance of pharmacy staff but more on the students and the community group.

\section{CONCLUSION}

Overall knowledge about OTC medications was low among the pharmacy staff, with slight differences in the knowledge level of the specialized pharmacists. Especially on OTC side effects, dosage, and reason for uses, which in term, increases the risk of OTC adverse effect on the consumers. The current study also concluded that, the years of working in pharmacy did not contribute to increasing their knowledge level about OTC, which is probably due to using same system during all working years and no improvements were noted even with attending multiple courses on OTC.

\section{CONFLICT OF INTEREST}

The researchers reported no conflict of interest.

\section{REFERENCES}

[1] Helal RM, Abou-EIWafa HS. Self-Medication in University Students from the City of Mansoura, Egypt. Journal of Environmental and Public Health. 2017;2017: 9145193. [Accessed 25.7.2019]Available from:https:// www.ncbi.nlm.nih.gov/pmc/articles/ PMC5396441/

[2] Le VT, Norris Turner A, McDaniel A, Hale KM, Athas C, Kwiek NC. Nonmedical use of over-the-counter medications is significantly associated with nonmedical use of prescription drugs among university students. Journal of Americans College Health. 2018;66(1):1-8.[ Accessed 7.5.2019] Available from: https://www.ncbi.nlm.nih.gov/ pubmed/28812451

[3] Khandeparkar A, Rataboli PV. A study of harmful drug-drug interactions due to polypharmacy in hospitalized patients in Goa Medical College. Perspectives in clinical research. 2017 Dec;8(4):180-6. [Accessed 5.6.2019] Available from: https:// www.ncbi.nlm.nih.gov/pmc/articles/ PMC5654218/

[4] Shehadeh M, Suaifan G, Darwish RM, Wazaify M, Zaru L, Alja'fari S. Knowledge, attitudes and behavior regarding antibiotics use and misuse among adults in the community of Jordan. A pilot study. Saudi Pharmaceutical Journal. 2012 Apr;20(2):125-33. [Accessed27.6.2019] Available from:https:// www.ncbi.nlm.nih.gov/pubmed/23960783

[5] Imani F, Motavaf M, Safari S, Alavian SM. The Therapeutic Use of Analgesics in Patients With Liver Cirrhosis: A Literature Review and Evidence-Based Recommendations. Hepat Mon. 2014 Oct; 14(10): e23539 [Accessed11.7.2019];14(10).Available from: https://www.ncbi.nlm.nih.gov/pmc/ articles/PMC4250965/ 
[6] Ahmad A, Khan MU, Srikanth AB, Kumar B, Singh NK, Trivedi N, et al. Evaluation of Knowledge, Attitude and Practice about Selfmedication Among Rural and Urban North Indian Population. National Journal of Community Medicine 2015;7(5):7. [Accessed 21.7.2019]Availablefrom:http:njcmindia.org/ uploads/NJCM_7-10_825-828.pdf

[7] Hamid SA. Consumer socialisation of over-the -counter medicines: a study of adolescents in New Zealand and Malaysia.2011;. [Accessed 18.7.2019]Availablefrom:https:// pdfs.semanticscholar.org/05b2/538c2bce98 dffd428f39ea3eda20fe3d5a29.pdf

[8] Kuku K, Odusanya O. Self Medication: Knowledge, Attitude and Practices in the Ikeja Local Govt. Area of Lagos Nigeria. 2011. [Accessed 12.6.2019]Available from:https:// www.researchgate.netpublication/21646859 8_Self_Medication_Knowledge_Attitude_and _Praties_in_the_lkeja_Local_Govt_Area_of_ Lagos_Nigeria

[9] Susheela F, Goruntla N, Bhupalam PK, Veerabhadrappa KV, Sahithi B, Ishrar SMG. Assessment of knowledge, attitude, and practice toward responsible self-medication among students of pharmacy colleges located in Anantapur district, Andhra Pradesh, India. Journal of Education and Health Promotion. 2018 Aug 2;7.[Accessed 17.6.2019] Availablefrom:https:/www.ncbi.nlm.nih.gov/ pmc/articles/PMC6088819/

[10] Ravichandran, A., Basavareddy, A. Perception of pharmacists regarding over-thecounter medication: A survey. Indian Journal ofPharmacology.2016.48,729-732. [Accessed 20.8.2019]Availablefrom:https:// doi.org/10.4103/0253-7613.194857

[11] Bastani P, Nia AA, Shabanpoor M, Mehravar S, Kashefian S. Knowledge, Attitude and Practice of Iranian Pharmacists, Body Builders, and Their Coaches Regarding Sports Supplements. Journal of Research of Pharmacy Practice. 2017;6(3):166-72. [Accessed 12.7.2019] Availablefrom: https:/ www.ncbi.nlm.nih.gov/pubmed/29026842

[12] Bj MK, A S, M S. A Survey on Assessing the Knowledge, Attitude and Behavior of Community Pharmacists to Adverse Drug Reaction Related Aspects. Saudi Pharmaceutical Journal. 2012;5(4):5.[Accessed 22.6.2019] Availablefrom:https:www.sciencedirect.com/ science/article/pii/S1319016413000868

[13] Ali A, Kai J, Keat CC, Dhanaraj S. Selfmedication practices among health care professionals in a Private University, Malaysia.International Current Pharmaceutical Journal.2012, 1(10): 302-310.[Accessed 15.7.2019]Available from: http:// www.icpjonline.com/documents/ Vol1Issue10/01.pdf

[14] Boateng DP. Self-medication among doctors and pharmacists at the Korle Bu teaching hospital. 2009. [Accessed 12.6.2019] Available from: https:// pdfs.semanticscholar.orgcde7/893bc37440 007e1dadae48ce544d410dfd93.pdf

[15] Shroti, R., Nayak, N., Rajput, M.S. A study on over the counter drugs in retail pharmacies in Indore city.Der Pharmacia Lettre, 2011, 3(3):133-138 [Accessed 17.9.2019] Available from: https:// www.scholarsresearchlibrary.com/articles/ a-study-on-over-the-counter-drugs-in-retail -pharmacies-in-indore-city.pdf 